\title{
Trends in diagnostic and therapeutic criteria in Graves' disease in the last 10 years
}

\author{
F Escobar-Jiménez, M L Férnandez-Soto, V Luna-López, M Quesada-Charneco, \\ D Glinoer
}

\begin{abstract}
A questionnaire describing a typical clinical case of Graves' disease and 10 variations on it was mailed to 70 Spanish units of endocrinology with the aim of assessing the new diagnostic and therapeutic trends for hyperthyroidism caused by Graves' disease in Spain and to compare the results obtained from previous studies carried out in Europe and Spain 10 years previously.

Responses indicated that thyrotrophin $(98 \%)$ and free thyroxine $(88 \%)$ were the most used tests in the in vitro diagnosis of Graves' disease with a significant decrease in the use of total thyroxine, total triiodothyronine, and thyroglobulin in comparison with the surveys conducted 10 years previously in Europe and Spain. The presence of antibodies against the thyrotrophin receptor was the most frequently used immune marker in the diagnosis $(78 \%)$ and the new use of antithyroperoxidase antibodies $(36 \%)$ in diagnosis is noteworthy. Antithyroid drugs remain the treatment of choice $(\mathbf{9 8 \%} \%$ ). Surgery was used mainly for large size goitres (33\%) and radioiodine for recurrences after medical $(61 \%)$ or surgical $(80 \%)$ treatment.

In conclusion, the responses obtained from this questionnaire provide insight into current specialist diagnostic and therapeutic practices with respect to Graves' disease and which could be of value to non-specialist units of endocrinology.

(Postgrad Med f 2000;76:340-344)
\end{abstract}

Keywords: Graves' disease; antithyroid drugs; radioiodine; surgery

Submitted 20 July 1999 Accepted 27 October 1999

Table 1 Descriptions of the basic case and hypothetical clinical variations

\begin{tabular}{llllll}
\hline Variation & $\begin{array}{l}\text { Age } \\
\text { (years) }\end{array}$ & Gender & $\begin{array}{l}\text { Severity of } \\
\text { hyperthyroidism }\end{array}$ & $\begin{array}{l}\text { Size of } \\
\text { goitre (g) }\end{array}$ & $\begin{array}{l}\text { First episode of } \\
\text { hyperthyroidism }\end{array}$ \\
\hline Basic case & 43 & F & Moderate & 40 & Yes \\
1 & 43 & F & Moderate & 80 & Yes \\
2 & 43 & F & Moderate & No goitre & Yes \\
3 & 43 & F & Severe & 40 & Yes \\
4 & 43 & F & Moderate & 40 & No: recurrence \\
5 & 43 & F & Moderate & 40 & No: recurrence \\
6 & 43 & M & Moderate & 40 & Yes \\
7 & 71 & F & Moderate & 40 & Yes \\
8 & 19 & F & Moderate & 40 & Yes \\
9 & 27 & 5 months pregnant & Moderate & 40 & No: recurrence \\
10 & 10 & F & Moderate & 40 & Yes \\
\hline
\end{tabular}

* Severe: pulse rate 150 beats/min; the patient has lost $7 \mathrm{~kg}$ during the last five weeks. +Recurrence: patient has been treated two years before with antithyroid drugs for one year. tRecurrence: patient was treated four years ago by subtotal thyroidectomy leaving, after surgery, $10-15 \mathrm{~g}$ of thyroid tissue.
The rapid expansion of knowledge on pathogeny, diagnosis, and treatment of Graves' disease over the last decade has prompted discussion in endocrinological societies' scientific sessions regarding the dissemination of information and awareness of new diagnostic and therapeutic aspects of the disease. In 1986 our team, supported by the Spanish Society of Endocrinology, conducted a survey ${ }^{1}$ in accordance with the original outlines of the European Thyroid Association and the first study of Glinoer et al in $1986 .{ }^{2}$

More recently, several differences became apparent in studies carried out in Japan ${ }^{3}$ and the United States ${ }^{4}$ and a new questionnaire for children with Graves' disease was published in Europe and to which our endocrine unit contributed. ${ }^{6}$

In the present survey, the responses are compared with the data we obtained 10 years ago as well as with the data collected in Europe in 1986. The new trends that have emerged for the diagnosis and treatment of Graves' disease are discussed.

\section{Methods}

STRUCTURE OF THE QUESTIONNAIRE

The questionnaire presented a case history describing a 43 year old woman without previous known pathology, presenting with typical symptoms and signs of hyperthyroidism of two months' duration. Examination showed tachycardia, diffuse goitre grade I-II, and few signs of exophthalmia. A questionnaire following the pattern previously used in published studies ${ }^{12}$ assessed the different in vivo and in vitro diagnoses of hyperthyroidism caused by Graves' disease as well as the therapeutic options. Also, a list of 10 variations to this basic case history was presented (table 1) so as to compare the differences in the choice of treatment elected for each variation.

The survey was sent to 70 specialist endocrine units in Spain and responses were received from 53 groups; some questionnaires were filled in as the consensus of a group and some as individuals. Finally, a total of 51 questionnaires from 14 autonomous regions were included in the present analysis (two were excluded for being incomplete).

\section{ANALYSIS OF QUESTIONNAIRE}

All responses were coded and statistically evaluated using the SPSS statistical package and RSIGMA compatible PC programs. Frequencies were adjusted on a $100 \%$ basis and rates comparison tests were performed. A p value of $<0.05$ was considered statistically significant. 
Table 2 In vivo diagnostic procedures; results are percentage of responses

\begin{tabular}{llll}
\hline Procedure & $\begin{array}{l}1997 \\
\text { (Spain) }\end{array}$ & $\begin{array}{l}\text { 1987 } \\
\text { (Spain) }\end{array}$ & $\begin{array}{l}1986 \\
\text { (Europe) }\end{array}$ \\
\hline Scintigraphy & 53 & $75^{\star}$ & 66 \\
Echography & 15 & 5 & 21 \\
Needle aspiration & 4 & 3 & \\
Reflex time & 2 & 3 & \\
Suppression test & 0 & 0 &
\end{tabular}

Significant differences between the present study and those performed in Spain in 1987 and in Europe in 1986: ${ }^{\star} \mathrm{p}<0.05$.

\section{Results}

DIAGNOSTIC PROCEDURES

The diagnosis of the basic clinical case was performed on an inpatient basis by $2 \%$ of respondents and on an ambulatory basis in $98 \%$ of them. There were no significant differences in these results compared to those from the surveys conducted in Spain and Europe in 1987 and 1986, respectively.

The most widely used in vivo method of diagnosis was scintigraphy but its use has declined in relation to the results of 1987 from 75 to $53 \%(\mathrm{p}<0.05)$. Technetium-99m $\left({ }^{99 \mathrm{~m}} \mathrm{Tc}\right)$ was the isotope of choice $(89 \%)$, followed by iodine-131 ( $\left.{ }^{131} \mathrm{I}\right)(11 \%)$; these results are similar to those of the 1987 Spanish study. The use of uptake remains very limited $(20 \%)$ and ${ }^{131} \mathrm{I}$ is used exclusively for this test.

Reflex time (2\%), thyroid echography $(15 \%)$, and cytology by fine needle aspiration $(4 \%)$ were used as diagnostic tests only by a minority of respondents. Table 2 shows the in vivo methods for the diagnosis of hyperthyroidism in decreasing order of frequencies, comparing them with the results from the surveys of 1986 and 1987.

Table 3 summarises the in vitro diagnostic preferences. The measurement of total thyroid hormones (thyroxine and triiodothyronine) in the hyperthyroidism associated with Graves' disease has markedly decreased in relation to $1987(18 \%$ v $94 \%$ and $35 \%$ v $91 \%$, respectively; $\mathrm{p}<0.001)$. The measurement of thyroid stimulating hormone (TSH) has become more general; the main techniques being the immunoradiometric assay method $(30 \%)$ followed by radioimmunoassay (18\%) and enzyme linked immunosorbent assay (ELISA) $(11 \%)$. The determination of free thyroxine is also notably increased in relation to the Spanish survey of $1987(88 \% v 50 \%)$ as well as the measurement of antibodies against TSH receptors $(78 \%)$ where significant differences $(p<0.001)$ were observed in relation to the results of the Spanish study of 1987. The diagnostic use of antithyroglobulin antibodies was significantly decreased relative to the survey of $1987(61 \%$ v $81 \% ; \mathrm{p}<0.05)$. The use of antimicrosomal antibodies was $63 \%$ v $81 \%$ $(\mathrm{p}<0.01)$ and the new use of the thyroid antithyroperoxidase antibody determination $(36 \%$ v $0 \% ; \mathrm{p}<0.001)$ is noteworthy. The measurement of thyroglobulin, indirect indices for free thyroxine, the thyrotrophin releasing hormone stimulated TSH test, and the urinary iodine excretion test have been virtually abandoned in clinical practice. The mean number of in vitro tests used by the respondents was 5.71 (range $2-11$ ).
Table 3 In vitro diagnostic procedures; results are percentage of responses

\begin{tabular}{llll}
\hline Test & $\begin{array}{l}1997 \\
\text { (Spain) }\end{array}$ & $\begin{array}{l}1987 \\
\text { (Spain) }\end{array}$ & $\begin{array}{l}1986 \\
\text { (Europe) }\end{array}$ \\
\hline Basal TSH & 98 & $52 \ddagger$ & $55 \ddagger$ \\
Free thyroxine & 88 & $50 \ddagger$ & $41 \ddagger$ \\
TSH antibody receptor & 78 & $20 \ddagger$ & $38 \ddagger$ \\
MIC-Ab & 63 & 78 & 63 \\
Tg-Ab & 61 & $81^{\star}$ & 62 \\
TPO-Ab & 36 & $0 \ddagger$ & $0 \ddagger$ \\
Total T3 & 35 & $91 \ddagger$ & $74 \ddagger$ \\
Cholesterol & 27 & 35 & $12^{\star}$ \\
Free T3 & 20 & 15 & 22 \\
Total thyroxine & 18 & $94 \ddagger$ & $74 \ddagger$ \\
Thyroglobulin & 10 & $29 \ddagger$ & $22^{\star}$ \\
TRH-TSH test & 4 & $40 \ddagger$ & $29 \ddagger$ \\
Free thyroxine index (T3) & 4 & 6 & $32 \ddagger$ \\
Free thyroxine index (TBG) & 0 & $9^{\star}$ & $11 \ddagger$ \\
Iodine excretion & 0 & 0 & $6^{\star}$
\end{tabular}

$\mathrm{MIC}-\mathrm{Ab}=$ antimicrosomal antibody; $\mathrm{T} 3$ = triiodothyronine; $\mathrm{TBG}=$ thyroxine binding globulin; $\mathrm{Tg}-\mathrm{Ab}=$ antithyroglobulin antibody; TPO-Ab = antithyroidperoxidase antibody; TRH = thyrotrophin releasing hormone; $\mathrm{TSH}=$ thyroid stimulating hormone.

Statistically significant differences between the results of the Spanish questionnaire of 1997 and those of the European and Spanish surveys of 1986 and 1987 , respectively: ${ }^{\star} \mathrm{p}<0.05$; $\mathrm{tp}<0.01 ; \ddagger \mathrm{p}<0.001$.

Table 4 Therapeutic options for the basic case and variations of Graves' disease; results are percentage of responses

\begin{tabular}{llll}
\hline Variation & Antithyroid drugs & ${ }^{131} I$ & Surgery \\
\hline Basic case & 98 & 2 & 0 \\
1 & 65 & 2 & 33 \\
2 & 100 & 0 & 0 \\
3 & 96 & 2 & 2 \\
4 & 33 & 61 & 6 \\
5 & 20 & 80 & 0 \\
6 & 96 & 4 & 0 \\
7 & 76 & 24 & 0 \\
8 & 100 & 0 & 0 \\
9 & 88 & 0 & 12 \\
10 & 100 & 0 & 0 \\
Total & 79.3 & 15.9 & 48 \\
\hline
\end{tabular}

GENERAL THERAPEUTICS

The treatment chosen for the index clinical case and its 10 different variations are presented in table 4 . These data are compared with those obtained from the Spanish and European surveys of 1987 and 1986, respectively, in fig 1 . In the basic case and in variations $2,3,6,7,8,9$, and 10 , the option of antithyroid drugs was the preferred treatment. In variations 1 and 7 , the percentage of respondents using antithyroid drugs increased from $29 \%$ to $65 \%$ (Spain 1987 and Europe $1986 v$ Spain 1997) and from 33\% to $76 \%$ (Spain 1987 and Europe 1986 v Spain 1997), respectively $(\mathrm{p}<0.001)$.

Surgery was chosen as treatment of choice in variation 1 by $33 \%$ of respondents, with a statistically significant decrease in relation to the survey of 1987 in which $62 \%$ of respondents had elected for thyroidectomy $(\mathrm{p}<0.01)$.

Ablation by radiotherapy continued to be the primary therapeutic option in variations 4 and 5 with the percentage of respondents similar to the 1987 survey $(51 \%$ v $64 \%$ and $80 \%$ v $79 \%$, respectively). In variation 7 , radioiodine was considered as the treatment of choice in the Spanish survey of 1987 (67\%) and was decreased to $24 \%$ in 1997 ( $\mathrm{p}<0.001)$. 

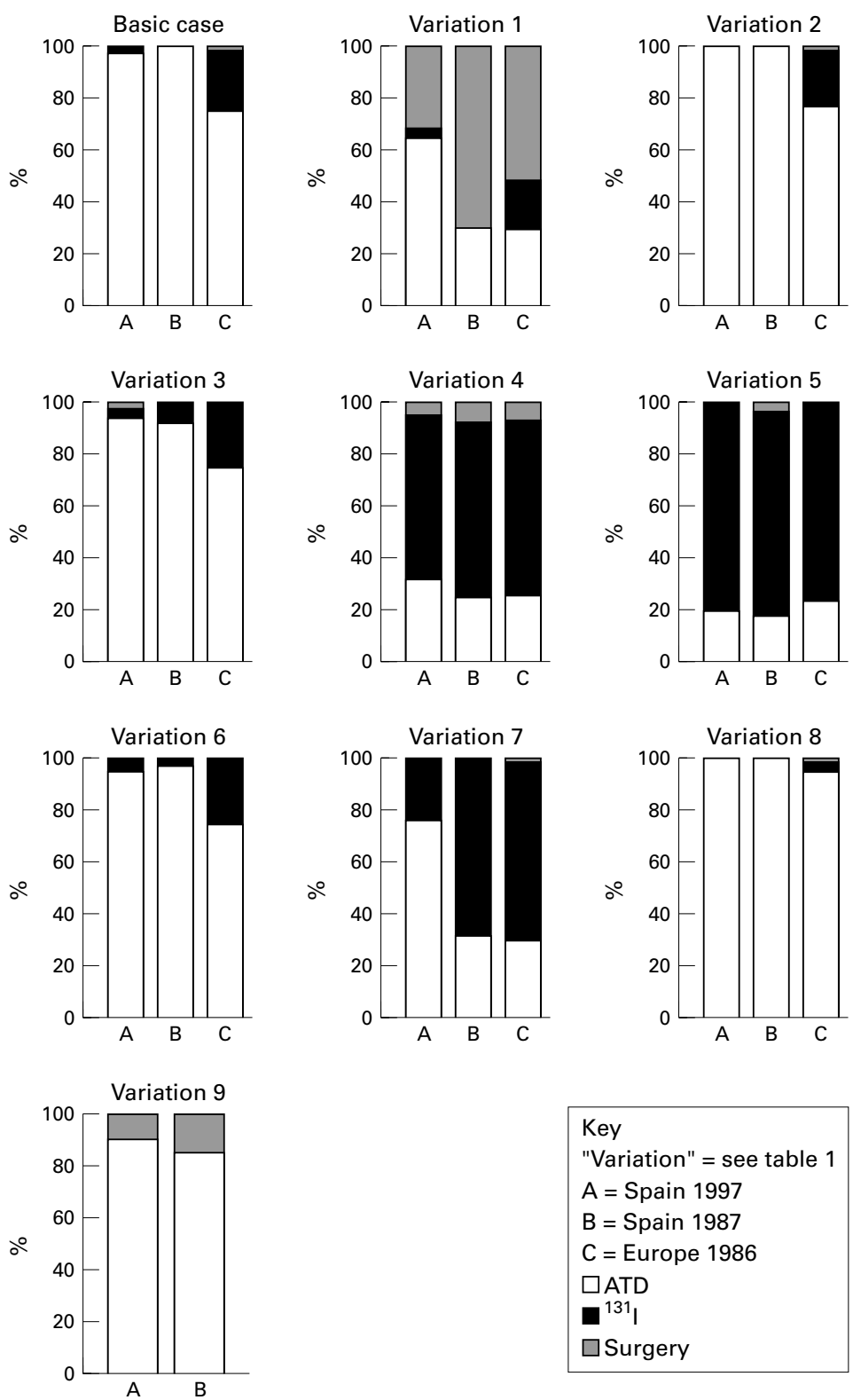

Figure 1 Comparison between the therapeutic options of the Spanish surveys of 1997 and 1987 and the European survey of 1986 (ATD=antithyroid drugs).

MEDICAL TREATMENT

Antithyroid drugs were the treatment chosen in the basic clinical case by most of the respondents in the present survey (98\%). Exclusively, methimazole (47\%) and carbimazole (53\%) were the drugs chosen. The most used initial dose of $30 \mathrm{mg} /$ day (range 15-45) was selected by $94 \%$ of the respondents ( $92 \%$ in 1987) and the choice was based on laboratory criteria alone in $6 \%$ of the respondents or based on clinical and laboratory criteria in $94 \%$ of respondents. These findings did not differ significantly from the Spanish survey of 1987.

The use of $\beta$-blockers was elected by $86 \%$ of the respondents; the majority of respondents $(84 \%)$ using these drugs only in the initial treatment, which was similar to the $86 \%$ and $80 \%$ respondents in the Spanish and European surveys of 1987 and 1986, respectively.

In the long term follow up, two groups of respondents were clearly differentiated: those
Table 5 Criteria for the withdrawal of medical treatment; results are percentage of responses

\begin{tabular}{lll}
\hline & 1997 & 1987 \\
\hline Fixed period & 71 & 58 \\
Variable period according to criteria & 29 & 42 \\
Clinical and biochemical euthyroidism & 88 & 96 \\
Normal TSH & $76^{\star}$ & 7 \\
Negative TSH antibody receptor & 36 & 48 \\
Normal thyroglobulin & $0^{\star}$ & 40 \\
Negative autoantibodies & $0^{\star}$ & 41 \\
Normal TRH-TSH & $0^{\star}$ & 78 \\
Normal suppression test & 0 & 0 \\
\hline
\end{tabular}

$\mathrm{TRH}=$ thyrotrophin releasing hormone; $\mathrm{TSH}=$ thyroid stimulating hormone.

Statistically significant differences are in relation to the results of the Spanish survey of 1987 : ${ }^{\star} \mathrm{p}<0.001$.

who only adjusted the antithyroid drug dose until euthyroidism was achieved $(65 \%)$ and those who opted for the use of antithyroid drugs in combination with thyroxine (35\%). This combination was chosen by $31 \%$ in the Spanish survey of 1987 and $45 \%$ in the European; the difference not being statistically significant. In the present survey, the mean dose of antithyroid drugs in the combination therapy was $27 \mathrm{mg} /$ day (range 10-45) and 105 $\mu \mathrm{g} /$ day (range 75-100) for thyroid hormone.

Treatment was maintained for a fixed period of $12-24$ months by $67 \%$ of respondents and for six months by $4 \%$ of them. The remaining $29 \%$ of respondents did not follow any established pattern and employed different criteria for deciding on cessation of treatment: clinical euthyroidism (88\%), normalisation of basal TSH $(76 \%)$, and negative findings in the measurement of antibodies against TSH receptors $(36 \%)$. Table 5 summarises the comparison with the studies conducted in Spain in 1987.

\section{RADIOIODINE}

The isotope of choice was, again, ${ }^{131} \mathrm{I}(97 \%)$ and was administered as a fixed dose by $7 \%$ of the respondents and $93 \%$ of respondents calculated the dose based on uptake and/or gland size. The administration of a single dose of ${ }^{131}$ I was preferred by $89 \%$ of respondents and $11 \%$ used smaller repeated doses. In the Spanish survey of 1987, a single dose was administered by $51 \%$ and small repeated doses were selected by $46 \%$ of specialists participating in the survey. The differences were statistically significant $(p<0.001)$. In contrast, the Europeans invariably (100\%) used ${ }^{131}$ I as a single dose.

When radioiodine was used after recurrence of hyperthyroidism after treatment with antithyroid drugs (variation 4), the aim of the therapy was to restore euthyroidism $(96 \%$ of respondents) and to achieve hypothyroidism $(4 \%)$. When ${ }^{131}$ I was used because of the recurrence of hyperthyroidism after near total thyroidectomy (variation 5), up to $30 \%$ of respondents aimed for hypothyroidism. Generally, in the Spanish survey of 1987 and the European survey of 1986 (93\% and $82 \%$, respectively), the main aim of the treatment with ${ }^{131} \mathrm{I}$ was to restore euthyroidism.

Medical treatment always included ${ }^{131} \mathrm{I}$. Antithyroid drugs and $\beta$-blockers were administered by $11 \%$ of respondents before ${ }^{131} \mathrm{I}, 15 \%$ 
after ${ }^{131} \mathrm{I}$ therapy, and by the majority of respondents $(74 \%)$ before as well as after the therapy.

SURGERY

Thyroidectomy was mainly selected (33\%) in variation 1 (hyperthyroidism with goitre grade III). Patients were prepared with antithyroid drugs alone or with $\beta$-blockers ( $100 \%$ of cases) and associated with Lugol's solution (88\%). The mean carbimazole dose used was 30 $\mathrm{mg} /$ day, methimazole $40 \mathrm{mg} / \mathrm{day}$, and $\beta$-blockers $70 \mathrm{mg} /$ day with an average preoperative treatment duration of six weeks.

The aim of $82 \%$ of respondents was euthyroidism (conservative surgery) while $18 \%$ opted to achieve hypothyroidism (radical surgery). Conservative surgery was also the option preferred in Spain in 1987 (95\%) and in Europe in 1986 (78\%). The differences were not statistically significant. Patient follow up was performed in an endocrine unit by $93 \%$ of respondents.

\section{OPHTHALMOPATHY}

The treatment of ophthalmopathy in Graves' disease has been one of the new questions raised by the survey. Of the respondents, $74 \%$ felt that in malignant exophthalmos nonresponsive to medical treatment, radiotherapy was the preferred therapeutic option while the other $26 \%$ preferred the surgical option.

\section{Discussion}

The detailed analysis of the 51 surveys included in this report indicated several deviations in the diagnosis and treatment of the disease compared with the results obtained a decade ago and reflects progress in the knowledge of the disease.

The first portion of the survey concerned diagnosis. The decreased use of scintigraphy compared with the trends observed in Europe in 1986 by Glinoer et $a l^{2}$ and in Spain in $1987^{1}$ in which the use of ${ }^{99 \mathrm{~m}} \mathrm{Tc}$ was the isotope of choice for in vivo diagnosis was similar to the observations in the Japanese and United States studies published in $1989^{3}$ and $1990 .{ }^{4}$ However a preference for the use of ${ }^{123} \mathrm{I}$ as isotope needs to be noted. ${ }^{78}$

In the in vitro diagnostic procedures, a decrease in the use of total thyroid hormone measurement and a notable increase in the use of free thyroxine and TSH determinations were observed and this reflects the greater reliability that these latter measurements have after the recent introduction of the immunoradiometric assay method. ${ }^{9}{ }^{10}$ The number of respondents systematically using the measurement of antibodies against TSH receptors and thyroid peroxidase is also increased and this demonstrates the increasing awareness of immunology factors in the aetiology of the disease. ${ }^{11}{ }^{12}$ The decreased use of free thyroxine indices and thyrotrophin releasing hormone stimulated $\mathrm{TSH}$ in the diagnosis of hyperthyroidism, as well as the virtual abandonment of urinary iodine measurement, confirmed the prediction of the European and the Spanish studies carried out 10 years ago. However, it is of note that some of the respondents still use indirect diagnostic tests such as thyroglobulin and total cholesterol, the practical utility of which are very questionable.

The second portion of the survey concerned the choice of treatment in the basic clinical case and variations of its presentation. The statistical analysis indicated that, in Spain, antithyroid drug therapy continues to be the preferred first line treatment compared with the European and Japanese studies carried out some years before. Different findings were observed by the American society in $1990^{4}$ and $1995^{13}$ in which ablation with radioiodine was the treatment of choice in uncomplicated Graves' disease (69\% of the American specialists consulted).

The analysis of the preferred options for the treatment of the variations on the basic presentation of Graves' disease showed interesting divergences. In variation 1 pharmacological treatment is the most often chosen and the percentage of use of surgery decreases significantly; this is the option that had been the most widely chosen by respondents from Spain and Europe in the previous decade. In variations $2,3,6$ and 8 , the trend of the previous surveys towards the preferred use of antithyroid drugs was maintained. Conversely, in variations 4 and 5 , the use of ${ }^{131} \mathrm{I}$ was the preferred choice for recurrences after antithyroid drug treatment or near total thyroidectomy; the main aim of this therapeutic option being to achieve euthyroidism as demonstrated in the previous Spanish and European studies. In variation 7 (a 71 year old woman) it is of note that the new trend is antithyroid drug therapy as the first option unlike the preferred option of ${ }^{131} \mathrm{I}$ of the Spanish and European studies of 1987 and 1986. Although there has been considerable interest in the recent literature regarding the use of ${ }^{131} \mathrm{I}$ and the progress of the ophthalmopathy, this question was not introduced into the questionnaire so as to maintain the same structure of the surveys in Europe, USA, and Spain over the past 10 years. The controversy over whether ${ }^{131}$ I adversely affects the ophthalmopathy persists and there have not been any homogeneous studies that resolve the issue of whether hypothyroidism following iodine therapy per se can be an independent risk factor for ophthalmopathy. Recently, Bartalena et al observed that radioiodine worsened the ophthalmopathy compared with the use of methimazole but, in the majority of cases $(65 \%)$, this was transitory for about three months. ${ }^{14}$ Variation 9 refers to a woman in the fifth month of pregnancy and, again, pharmacological treatment was the preferred choice. The use of propylthiouracil was the priority choice for most of the specialists consulted; this is quite surprising considering the poor availability of the drug in most of the hospitals in Spain. Only $12 \%$ of respondents administered methimazole in the treatment of hyperthyroidism to this woman and in no instance were $\beta$-blockers employed, and this indicates the general awareness of the contraindications of the latter drug in pregnant women. ${ }^{15}$ Surgical treatment was consid- 
ered to be the safest therapeutic option for pregnant patients by $12 \%$ of respondents.

In variation 10 the specialists were asked to specify the treatment of a 10 year old girl with moderate goitre and presenting with a first episode of hyperthyroidism. All the respondents considered antithyroid drug therapy as the initial basic treatment in uncomplicated Graves' disease and this is in accordance with the observations by Perrild et al in Europe in $1993 .{ }^{6}$ In the present study, surgery was only considered in case of recurrences after pharmacological treatment or in the presence of adenoma, nodular or large size goitre. Ablation with radioiodine was preferred for recurrences after near total thyroidectomy or treatment with antithyroid drugs.

In summary, we confirm the Spanish and European preference for a more conservative treatment with the use of antithyroid drugs as treatment of choice in most of the modalities of hyperthyroidism due to Graves' disease. This is in contrast to the therapeutic preferences observed by Japanese and American investigators. Surgical treatment appears to be confined to recurrences of hyperthyroidism previously treated with antithyroid drugs and/or to large size goitres. Similarly, radioiodine is only used in hyperthyroid recurrence after pharmacological treatment or goitre surgery. Since the three modalities of treatment have advantages as well as inconveniences, ${ }^{16}$ perhaps the greater use of ${ }^{131} \mathrm{I}$ as the first line option is preferable as it is a more radical method and with low chance of relapse compared with antithyroid therapy, at least in the short term. ${ }^{17}$ However, further clinical trials need to be conducted to elucidate this as well as other issues. The maintenance of large scale directories would be essential to assess long term outcomes and to inform current practice.

We thank all the Spanish teams and individual professionals for the invaluable help in providing clinical information. We also thank Sr Felipe Gómez for his diligence in the distribution and subsequent collection of the questionnaires.

1 Fernández-Soto $M$, Escobar-Jiménez $\mathrm{F}$, González-Jiménez A, et al. Diagnostico y tratamiento de la enfermedad de Graves. Resultados de una encuesta nacional en 1987. Endocrinología 1988;35:166-74.

2 Glinoer D, Hesch D, Lagasse R, et al. The management of hyperthyroidism due to Graves' disease in Europe in 1986. Results of an international survey. Acta Endocrinol (Copenh) 1987;115(suppl 285):3-23.

3 Nagayama Y, Izumi $M$, Nagataki S. The management of hyperthyroidism due to Graves' disease in Japan in 1988. Endocrinol fpn 1989;36:299-314.

4 Solomon B, Glinoer D, Lagasse R, et al. Current trends in the management of Graves' disease. F Clin Endocrinol Metab 1990;70:1518-24.

5 Glinoer D. The diagnosis and treatment of Graves' disease in Europe. Differences and similarities with Japan and the United States. Eur f Intern Med 1992;3 (suppl 1):84-96.

6 Perrild P, Grüters-Kieslich A, Feld-Ragmussen U, et al. Diagnosis and treatment of thyrotoxicosis in childhood. A European questionnaire study. Eur $\mathcal{F}$ Endocrinol 1994;131: 467-73.

7 Wartofsky L, Glinoer D, Solomon B, et al. Differences and similarities in the diagnosis and treatment of Graves' disease in Europe, Japan and the United States. Thyroid 1991;1: 129-35.

8 Cavalieri RR. Thyroid radioiodine uptake: indications and interpretation. Endocrinologist 1992;2:341-7.

9 Nicoloff JT, Spencer CA. The use and misuse of the sensitive tyrotropin assays. F Clin Endocrinol Metab 1990;71:5538 .

10 Hay ID, Bayer MF, Kaplan MM, et al. American Thyroid Association assessment of current free thyroid hormone and thyrotropin measurements and guidelines for future clinical assays. Clin Chem 1991;37:2002-8.

11 Schiferdecker E, Kuhnl P, Schoffling K. Immunogenetic Schiferdecker E, Kuhnl P, Schoffling K. Immunogenetic
markers in patients with Graves' disease. Klinische Wochenschrift 1991;69:256-60.

12 Campos Pastor MM, Fernández-Soto ML, EscobarJiménez F, et al. Evolución inmunológica y de la función tiroidea a largo plazo en la enfermedad de Graves según distintas opciones terapéuticas. Med Clin (Barc) 1994;102: 446-50.

13 Singer PA, Cooper DS, Levy EG, et al. Treatment guidelines for patients with hyperthyroidism and hypothyroidism. ҰAMA 1995; $273: 808-17$

14 Bartalena L, Marcocci B, Bogazzi F, et al. Relation between therapy for hyperthyroidism and the course of Graves ophthalmopathy. N Engl f Med 1998;338:73-8.

15 Pruyn SC, Phelan JP, Buchanan GC. Long-term propranolol therapy in pregnancy: maternal and fetal outcome. Am f Obstet Gynecol 1979;135:485-9.

16 Leech NJ, Dayan CM. Controvesies in the management of Graves disease. Clin Endocrinol (Oxf) 1998;49:273-80.

17 Tórring O, Tallstedt L, Wallin G, et al. Graves' hyperthyroidism treatment with antithyroid drugs, surgery or radioiodine- a prospective randomized study. F Clin Endocrinol Metab 1996;81:2986-93. 